\title{
Combination of ERK2 and STAT3 Inhibitors Promotes Anticancer Effects on Acute Lymphoblastic Leukemia Cells
}

\author{
EWA JASEK-GAJDA ${ }^{1}$, HALINA JURKOWSKA ${ }^{2}$, MAŁGORZATA JASIŃSKA ${ }^{1}$, \\ JAN A. LITWIN ${ }^{1}$ and GRZEGORZ J. LIS ${ }^{1}$ \\ ${ }^{1}$ Department of Histology, Faculty of Medicine, Jagiellonian University Medical College, Kraków, Poland; \\ ${ }^{2}$ Chair of Medical Biochemistry, Faculty of Medicine, Jagiellonian University Medical College, Kraków, Poland
}

\begin{abstract}
Background/Aim: Deregulated activation of signaling through the RAS/RAF/mitogen-activated protein kinaselextracellular signal-regulated kinase (RAS/RAF/MEK/ $E R K)$ and signal transducer and activator of transcription (STAT) pathways is involved in numerous hematological malignancies, making it an attractive therapeutic target. This study aimed to assess the effect of the combination of ERK2 inhibitor VX-11e and STAT3 inhibitor STA-21 on acute lymphoblastic leukemia cell lines REH and MOLT-4. Materials and Methods: REH and MOLT-4 cell lines were cultured with each drug alone and in combination. Cell viability, ERK activity, cell cycle distribution, apoptosis and oxidative stress induction were assessed by flow cytometry. Protein levels of STAT3, phospho-STAT3, protein tyrosine phosphatase $4 A 3$ (PTP4A3), survivin, $p 53$ and $p 21$ were determined by western blotting. Results: VX-11e in combination with STA-21 significantly inhibited cell viability, induced $G_{0} / G_{I}$ cell-cycle arrest, enhanced production of reactive oxygen species, and induced apoptosis. These effects were associated with an increased level of $p 21$ protein in REH cells and with reduced levels of phopho-STAT3, survivin and PTP4A3 proteins in MOLT-4 cells. Conclusion: Our findings provide a rationale for combined inhibition of RAS/RAF/MEK/ERK and STAT3 pathways in order to enhance anticancer effects against acute lymphoblastic leukemia cells.
\end{abstract}

Acute lymphoblastic leukemia (ALL) is the most common hematological malignancy in children and adolescents, and includes B-lineage acute lymphocytic leukemia (B-ALL), which constitutes $25 \%$ of all cancer in children, and T-lineage

This article is freely accessible online.

Correspondence to: Ewa Jasek-Gajda, Department of Histology, Jagiellonian University Medical College, Kopernika 7, PL-31034 Krakow, Poland. Tel: +48 124227027, e-mail: ewa.jasek@uj.edu.pl

Key Words: ERK, STAT3, apoptosis, cell cycle, ROS, ALL. acute lymphoblastic leukemia (T-ALL), which occurs at a lower frequency and is associated with a worse prognosis (1, 2). ALL cells display dysregulation of several intracellular signaling pathways including RAS/RAF/mitogen-activated protein kinase/extracellular signal-regulated kinase (RAS/RAF/MEK/ERK) and signal transducer and activator of transcription (STAT) pathways, which are relatively common (3).

Protein kinases ERK1/2 are central signaling kinases that control cell proliferation, survival, differentiation and apoptosis. ERK1/2 phosphorylates multiple substrates localized in different subcellular compartments and activates the expression of many regulatory proteins involved in the cell cycle and apoptosis, including p21 and survivin (4-7).

Recently, the RAS/RAF/MEK/ERK signal transduction pathway has become an important target in cancer treatment research. VX-11e, a selective ERK2 inhibitor, has been shown to reduce growth of melanoma xenografts and to reduce survival of various human cancer cell lines $(8,9)$. It has also been found to induce cell-cycle arrest and apoptosis in leukemia cell lines (10).

STAT3 is an important transcription factor. Once phosphorylated, it regulates the expression of numerous transcriptional targets, such as $\mathrm{p} 53, \mathrm{p} 21$, protein tyrosine phosphatase 4A3 (PTP4A3) and survivin (11, 12). Dysregulation of STAT3 contributes to oncogenesis by changing the expression of genes regulating the cell cycle and cell growth, leading to disruption of these processes. Moreover, abnormal expression of activated STAT3 can also prevent apoptosis through up-regulation of anti-apoptotic proteins (13). Since STAT3 is frequently activated in ALL, it represents a promising target for the development of a new approach in the treatment of ALL (14).

STA-21 is a small molecule that inhibits STAT3 DNAbinding activity and STAT3-STAT3 dimerization. It has been shown to reduce the survival of breast cancer cells that express constitutively active STAT3 (15). Moreover, STA-21 was found to induce a dose-dependent increase in apoptotic cells in T-cell large granular lymphocyte leukemia (16). 
To enhance therapeutic response in ALL, new strategies have recently been proposed, including combinations of drugs affecting the RAS/RAF/MEK/ERK pathway and other molecular targets. Accordingly, a synergistic effect was observed for ERK2 inhibitor in combination with megestrol in T-cell prolymphocytic leukemia cells (17). In our previous studies, we also demonstrated that MEK1/2 and ERK2 inhibitors in combination with voreloxin increased antiproliferative and pro-apoptotic effects in leukemia cells (10, 18). Recently, it was reported that combination of MEK and STAT3 inhibitors enhanced therapeutic response in pancreatic ductal adenocarcinoma (19).

The aim of this study was to determine the effect of ERK2 inhibitor VX-11e in combination with STAT3 inhibitor STA21 on viability, cell-cycle distribution and apoptosis of human lymphoblastic leukemia cells.

\section{Materials and Methods}

Inhibitors. STA-21 and VX-11e were obtained from Selleck Chemicals (Selleckchem, Houston, TX, USA) and dissolved in dimethyl sulfoxide (DMSO; Merck Millipore, Billerica, MA, USA). Stock solutions were kept at $-20^{\circ} \mathrm{C}$ until use. In drug combination experiments, the final concentration of DMSO, which was used as vehicle control, did not exceed $0.1 \%$.

Cell lines and cell culture. The human cell lines REH (B-ALL) and MOLT-4 (T-ALL) were purchased from German Collection of Microorganisms and Cell Cultures (DSMZ, Braunschweig, Germany) and grown in RPMI-1640 GlutaMax medium containing 10\% fetal bovine serum (FBS), $100 \mathrm{U} / \mathrm{ml}$ penicillin, and $100 \mu \mathrm{g} / \mathrm{ml}$ streptomycin (all reagents were obtained from Life Technologies, Carlsbad, CA, USA). The cells were cultured at $37^{\circ} \mathrm{C}$ in a humidified atmosphere with $5 \% \mathrm{CO}_{2}$.

Cell viability assay. REH and MOLT- 4 cells were seeded in triplicate at a density of $2 \times 10^{4}$ cells/well in a 96-well plate. Cells were treated with either DMSO (control) or different concentrations of STA-21 $(2.5,5,10,20$ or $40 \mu \mathrm{M})$ for 24 and $48 \mathrm{~h}$. For combination drug treatment, cells were simultaneously exposed to $4 \mu \mathrm{M}$ of VX-11e with $5 \mu \mathrm{M}$ of STA-21 for $48 \mathrm{~h}$. The Muse Count and Viability Assay Kit (Merck Millipore) was used to assess cell viability according to the manufacturer's instructions. Briefly, cells were incubated with the Muse Count and Viability Reagent for $5 \mathrm{~min}$ at room temperature and quantified using Muse Cell Analyzer (Merck Millipore). The relative cell viability was expressed as the percentage relative to that of control cells.

ERK activity assay. REH and MOLT- 4 cells were seeded in triplicate in a 96-well plate at a density of $2 \times 10^{4}$ cells/well and treated with vehicle or with each agent alone or in combination ( $4 \mu \mathrm{M}$ of VX$11 \mathrm{e} / 5 \mu \mathrm{M}$ of STA-21) for $48 \mathrm{~h}$. The Muse MAPK Activation Dual Detection Kit (Merck Millipore), including anti-phospho-ERK1/2 (Thr202/Tyr204, Thr185/Tyr187)-phycoerythrin (PE) and antiERK1/2-PECy5 antibodies, was used to evaluate ERK phosphorylation relative to the total ERK expression in REH and MOLT- 4 cell lines. The cells were fixed, permeabilized and incubated with antibodies for $30 \mathrm{~min}$ at room temperature in the dark according to the manufacturer's instructions. The cells were analyzed using Muse Cell Analyzer.

Cell-cycle analysis. ALL cell lines were seeded in triplicate in a 24well plate at a density of $10^{5}$ cells/well and treated with vehicle or with $4 \mu \mathrm{M}$ of VX-11e/5 $\mu \mathrm{M}$ of STA-21 for $48 \mathrm{~h}$. The cell-cycle distribution was evaluated using the Muse Cell Cycle Kit (Merck Millipore) according to the manufacturer's protocol with some modifications. Briefly, $10^{5}$ control and treated cells were fixed overnight with $70 \%$ ice-cold ethanol at $-20^{\circ} \mathrm{C}$ and then incubated with Cell Cycle Reagent for $20 \mathrm{~min}$ at room temperature in the dark. All samples were analyzed on a Muse Cell Analyzer.

Apoptosis assay. REH and MOLT-4 cells were seeded at a density of $10^{5}$ cells/well in triplicate, in a 24 -well plate and incubated with vehicle or with each inhibitor alone or in combination $(4 \mu \mathrm{M}$ of VX$11 \mathrm{e} / 5 \mu \mathrm{M}$ of STA-21) for $48 \mathrm{~h}$. For assessment of apoptotic cells, the Muse Annexin V and Dead Cell Kit (Merck Millipore) was used according to the manufacturer's instructions. This assay utilizes Annexin V to detect apoptotic cells and a dead cell marker, 7aminoactinomycin D as an indicator of cell membrane integrity. In brief, 105 control and treated cells were re-suspended in phosphatebuffered saline supplemented with 1\% FBS and Muse Annexin V and Dead Cell Reagent for $20 \mathrm{~min}$ at room temperature in the dark. The cells were quantified using Muse Cell Analyzer.

Oxidative stress assay. REH and MOLT-4 were seeded in triplicate in a 96-well plate $\left(2 \times 10^{5}\right.$ cells/well $)$ and treated with vehicle alone or with $4 \mu \mathrm{M}$ of VX-11e/5 $\mu \mathrm{M}$ of STA-21 for $48 \mathrm{~h}$. The cell population undergoing oxidative stress was measured using the Muse Oxidative Stress Kit (Merck Millipore) according to the manufacturer's protocol. Briefly, cells were re-suspended in Muse Oxidative Stress working solution containing dihydroethidium (DHE) and incubated for $30 \mathrm{~min}$ at $37^{\circ} \mathrm{C}$. The cells were quantified using Muse Cell Analyzer and the relative percentage of reactive oxygen species (ROS) positive- and ROS-negative cells was estimated by Muse analysis software.

Western blotting. Total protein was extracted from control and treated cells using RIPA buffer (Sigma-Aldrich Corp., St. Louis, MO, USA) supplemented with 1X Protease Inhibitor Cocktail (Roche Diagnostic, Basel, Switzerland) followed by centrifugation at 20,000 $\times g$ for $15 \mathrm{~min}$ at $4^{\circ} \mathrm{C}$. Protein concentrations were determined by bicinchoninic acid assay (Thermo Scientific/Pierce Biotechnology, Rockford, IL, USA). Protein samples $(25 \mu \mathrm{g})$ were separated by sodium dodecyl sulfate polyacrylamide gel electrophoresis using $12 \%$ sodium dodecyl sulfate, and then electrotransferred to polyvinylidene fluoride membranes (BioRad Laboratories, Hercules, CA, USA). The membranes were blocked with $5 \%$ non-fat milk and incubated overnight at $4{ }^{\circ} \mathrm{C}$ with primary antibodies (Cell Signaling Technology, Danvers, MA, USA): Mouse monoclonal anti-STAT3 (\#9139, 1:1000); mouse monoclonal antiphospho-STAT3 (pSTAT3), (\#4113, 1:800); rabbit polyclonal antiPTP4A3 (\#6484, 1:800); rabbit monoclonal anti-survivin (\#2808, 1:1000); rabbit monoclonal anti-p53 (\#2527, 1:500); rabbit monoclonal anti-p21 Waf1/Cip21 (\#2947, 1:1000); and rabbit monoclonal anti- $\beta$ actin (\#4970, 1:1000). After washing, the membranes were incubated with goat anti-rabbit/ anti-mouse secondary antibodies conjugated with alkaline phosphatase (1:2000; Proteintech Group. Inc., Rosemont, IL, USA). Bands were developed using 5-bromo-4-chloro-3-indolyl phosphate/nitro blue tetrazolium (Roche Diagnostic) as substrate. The 
A

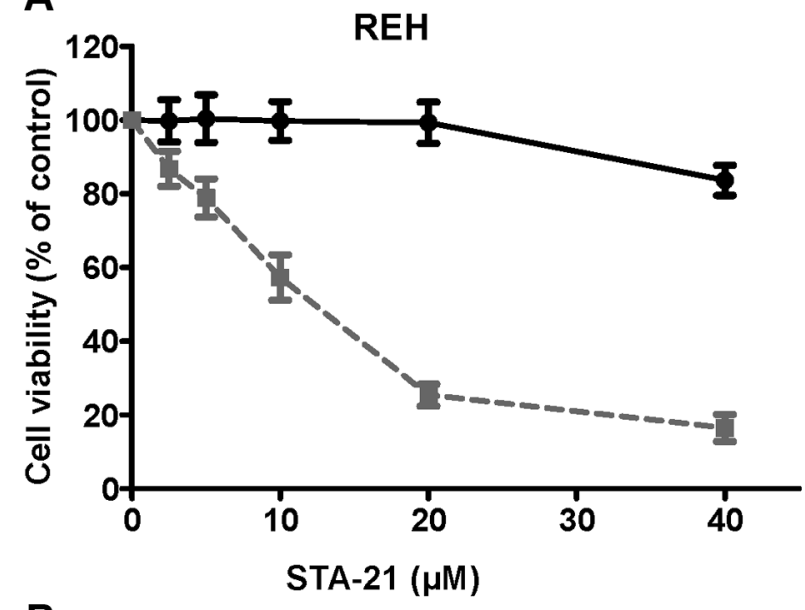

B

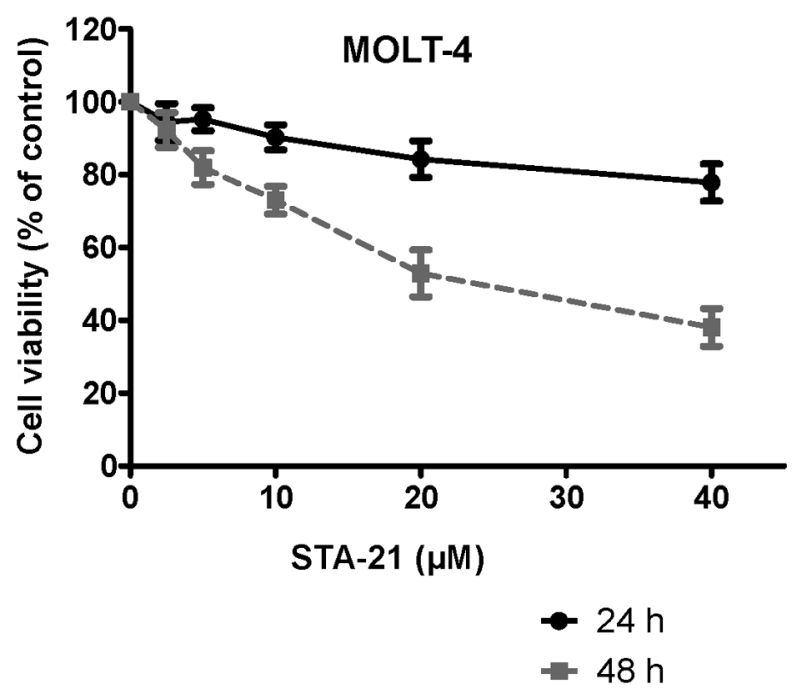

C

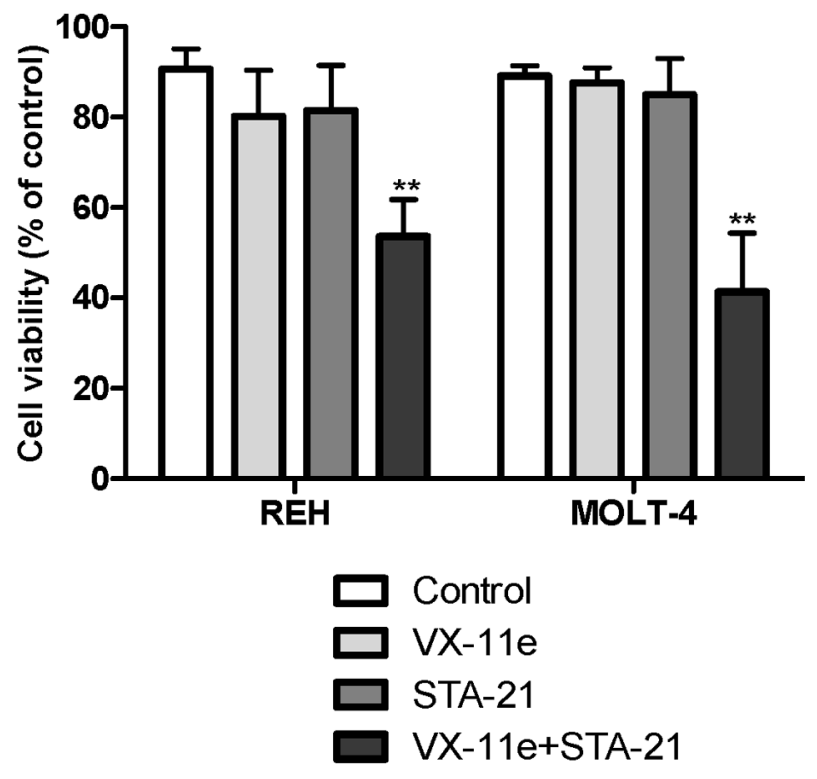

Figure 1. Signal transducer and activator of transcription-3 (STAT3) inhibitor STA-21, alone and in combination with extracellular-regulated kinase (ERK) 2 inhibitor VX-11e inhibited acute lymphoblastic leukemia cell viability. REH $(A)$ and MOLT-4 cells $(B)$ were exposed to STA-21 alone at increasing concentrations for 24 and $48 \mathrm{~h}$ and to a combination of $4 \mu \mathrm{M}$ VX11e with $5 \mu M$ STA-21 for $48 h(C)$. The cell viability was determined by Muse Count and Viability Kit. Each value is the mean $\pm S D$ of three independent experiments. **Significantly different at $p<0.01 \mathrm{vs}$. control. optical density of the bands was quantified with ChemiDoc MP Imaging System (Bio-Rad Laboratories, Hercules, CA, USA). $\beta$-Actin was used for normalization.

Statistical analysis. GraphPad Prism 5.0 (GraphPad Software Inc., La Jolla, CA, USA) was used for the statistical analysis. The results are presented as the mean \pm standard deviation $(\mathrm{SD})$ of three independent experiments. Statistical differences were analyzed by Mann-Whitney or Student's $t$-test with values of $p<0.05$ as statistically significant.

\section{Results}

STA-21 alone and in combination with VX-11e inhibits cell viability. REH and MOLT-4 cells were treated with increasing concentrations of STA-21 (2.5 to $40 \mu \mathrm{M})$ for 24 and $48 \mathrm{~h}$. The cell viability decreased in a dose- and time-dependent manner in both cell lines (Figure 1A and B). A concentration of $5 \mu \mathrm{M}$ STA-21 was selected for all subsequent experiments, as the highest concentration exhibiting relatively low toxicity to treated cells after $48 \mathrm{~h}(\sim 80 \%$ viability $)$. A concentration of 4 $\mu \mathrm{M}$ VX-11e was chosen on the basis of our previous study (18). The combination of non-toxic concentration of $4 \mu \mathrm{M}$ VX-11e and $5 \mu \mathrm{M}$ STA-21 significantly inhibited cell viability of REH and MOLT-4 cells as compared with the effects of each drug used alone (Figure 1C).

VX-11e and STA-21 reduce ERK activity. The use of VX-11e alone and in combination with STA-21 for $48 \mathrm{~h}$ significantly reduced the percentage of ERK-activated cells in both cell lines, reaching the lowest level in REH cells treated with both inhibitors $(22.3 \% \pm 7.2 \%)$. STA-21 alone significantly reduced ERK activity in the MOLT- 4 cell line compared to control cells (Figure 2). These results therefore indicate that the combination of VX-11e and STA-21 is highly effective in the inhibition of ERK activity in REH and MOLT-4 cells. 
A

REH
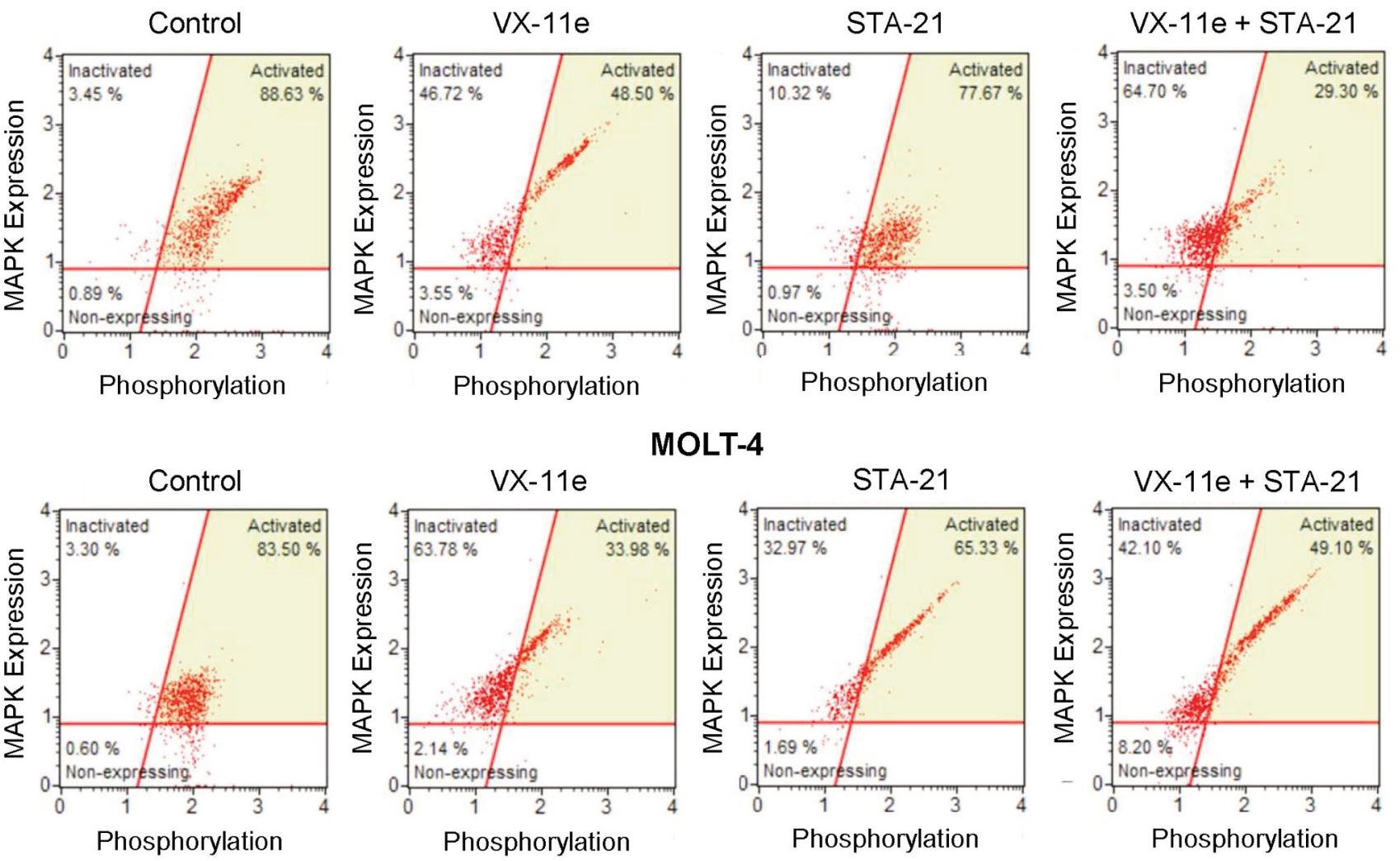

\section{MOLT-4}
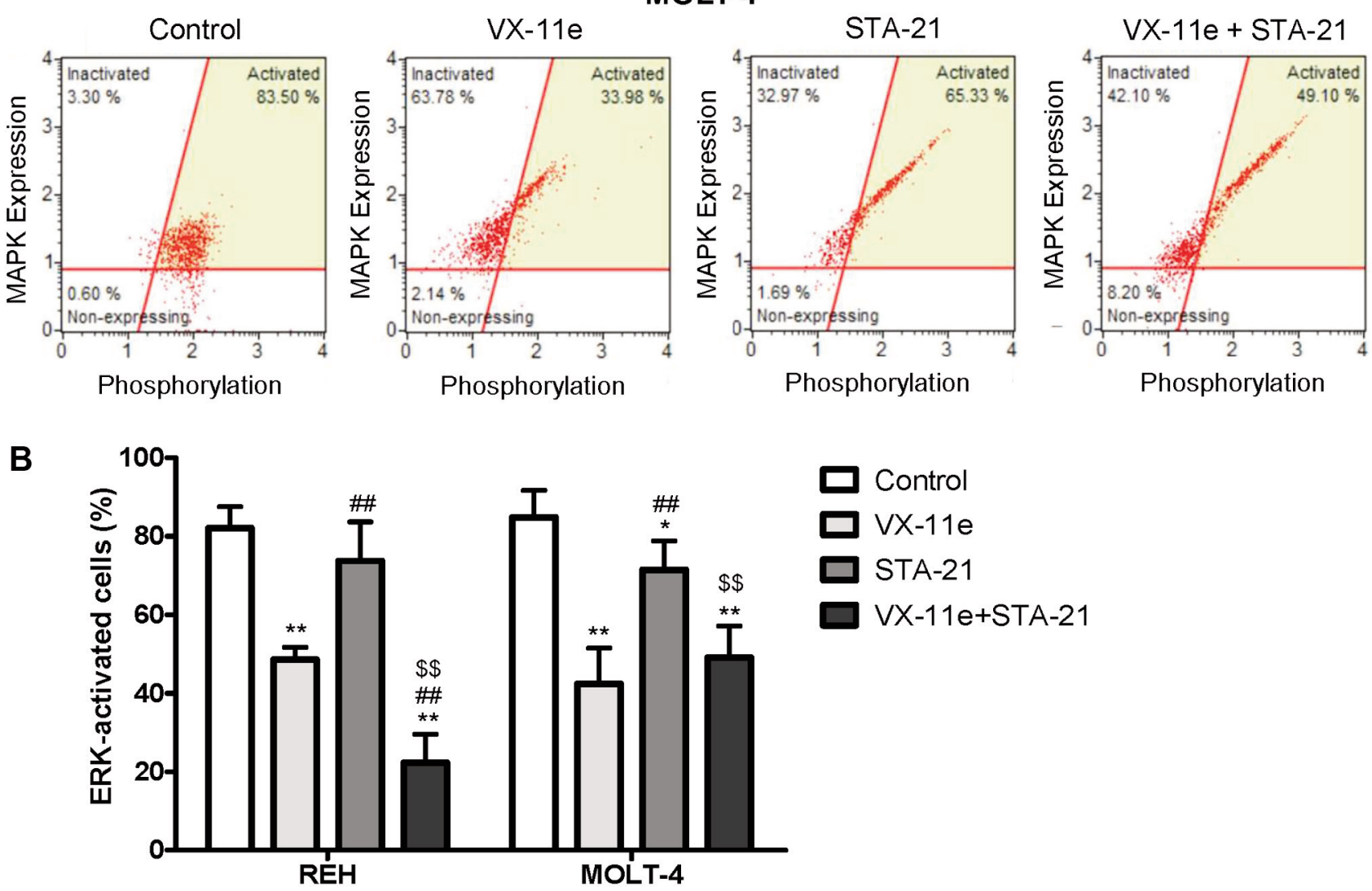

Figure 2. Extracellular-regulated kinase (ERK) 2 inhibitor VX-11e and signal transducer and activator of transcription-3 (STAT3) inhibitor STA-21, alone and in combination, reduced ERK activity. REH and MOLT-4 cells were incubated for $48 \mathrm{~h}$ with $4 \mu M$ VX-11e and $5 \mu M$ STA-21, alone and in combination. ERK activation was determined using Muse MAPK Activation Dual Detection Kit. Representative dot plots of mitogen-activated protein kinase (MAPK) expression (A) and graph of ERK activation (B) in REH and MOLT-4 cell lines. Each value is the mean \pm SD of three independent experiments. Significantly different at: ${ }^{*} p<0.05$, and ${ }^{* *} p<0.01 \mathrm{vs.} \mathrm{control;}{ }^{*} p<0.01 \mathrm{vs}$. VX-11e alone; $\$ \$ p<0.01$ vs. STA-21 alone.

Combined treatment with VX-11e and STA-21 induces cellcycle arrest and apoptosis. VX-11e and STA-21 alone did not significantly affect the cell cycle, whereas combined treatment significantly increased the proportion of REH and MOLT- 4 cells in the $G_{0} / G_{1}$ phase, with a corresponding decrease of the percentage of cells in the $\mathrm{G}_{2} / \mathrm{M}$ phase (Figure 3).

VX-11e significantly increased the total apoptotic rate (early and late apoptosis) to approximately $20 \%$ of both cell lines, whereas STA-21 alone induced this process in about 
A

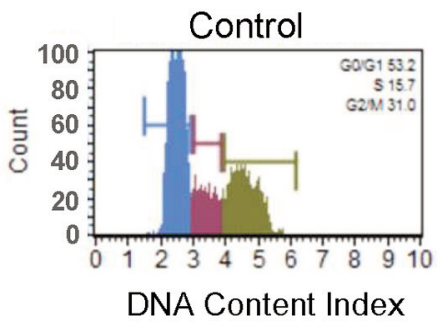

REH
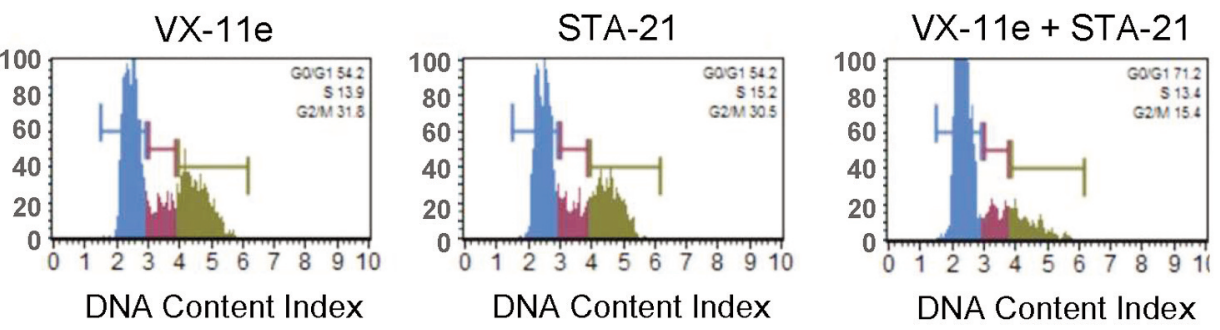

MOLT-4
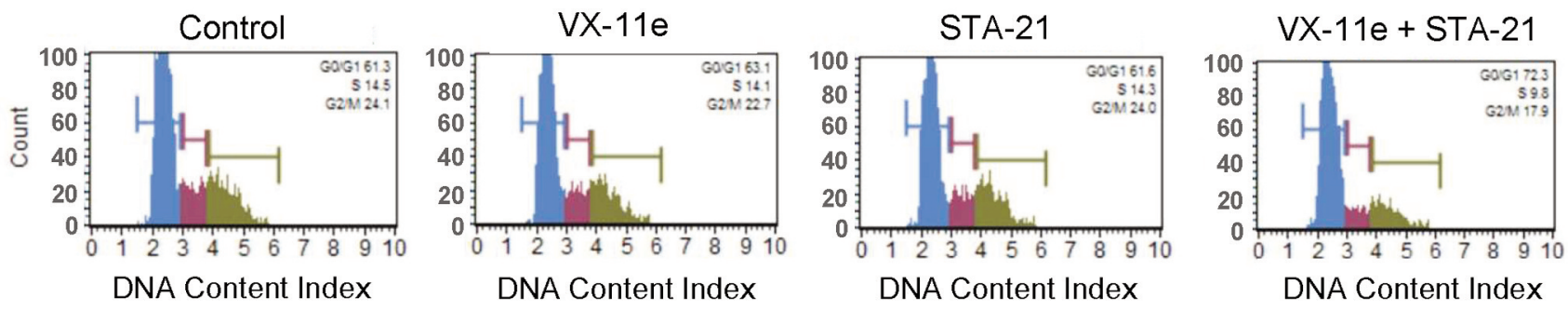

B

REH
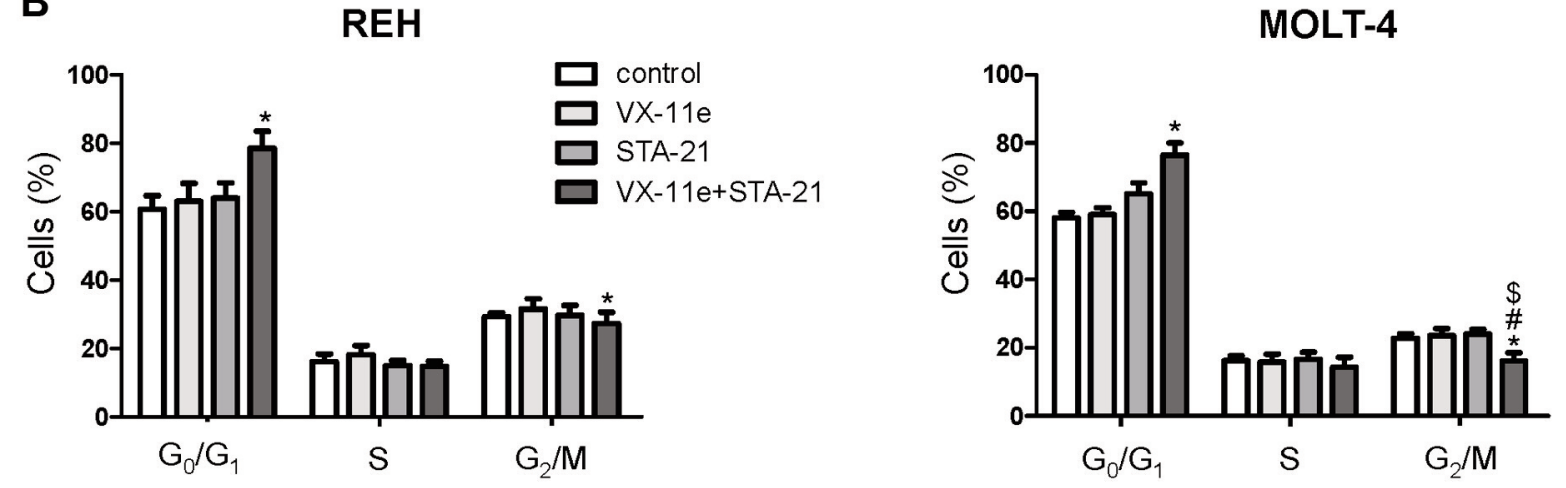

Figure 3. Combination of extracellular-regulated kinase (ERK) 2 inhibitor VX-11e and signal transducer and activator of transcription-3 (STAT3) inhibitor STA-21 induced cell-cycle arrest. REH and MOLT-4 cells were incubated for $48 h$ with $4 \mu M$ VX-11e and $5 \mu M$ STA-21, alone and in combination. Representative histograms from Muse Cell Cycle assay (A) and graphs (B) showing the percentage of REH and MOLT-4 cells at various stages of the cell cycle. Each value is the mean $\pm S D$ of three independent experiments. Significantly different at: *p<0.05 vs. control; \#p<0.05 vs. VX11e alone; ${ }^{\$} p<0.05$ vs. STA-21 alone.

$10 \%$ of MOLT-4 cells and $30 \%$ of REH cells (Figure 4 ). As compared to the effect of each drug alone, the combined treatment resulted in further increase in the percentage of apoptotic cells from $50.9 \% \pm 9.7 \%$ in MOLT-4 cells to $65.9 \% \pm 9.6 \%$ in REH cells. These results demonstrate that the combined treatment with VX-11e and STA-21 enhances apoptosis in REH and MOLT-4 cells and this can be attributed to cell-cycle perturbations.

STA-21 alone and in combination with VX-11e increases ROS production. VX-11e reduced the percentage of ROS-positive REH cells and had no significant effect on oxidative stress induction in MOLT-4 cells. In both cell lines, a significant increase in the percentage of ROS-positive cells $(25.9 \% \pm 2.3 \%$ in MOLT- 4 cells and $72.5 \pm 1.6 \%$ in REH cells) was observed after treatment with STA-21 and this effect was markedly potentiated in MOLT-4 cells after combination of STA-21 with VX-11e $(60.5 \% \pm 7.6 \%)$ (Figure 5). The results suggest that STA-21 promotes the generation of intracellular ROS, leading to oxidative stress.

Combination of VX-11e and STA-21 alters levels of some apoptosis-related proteins in ALL cell lines. To further confirm the pro-apoptotic effect of VX-11e and STA-21 in 

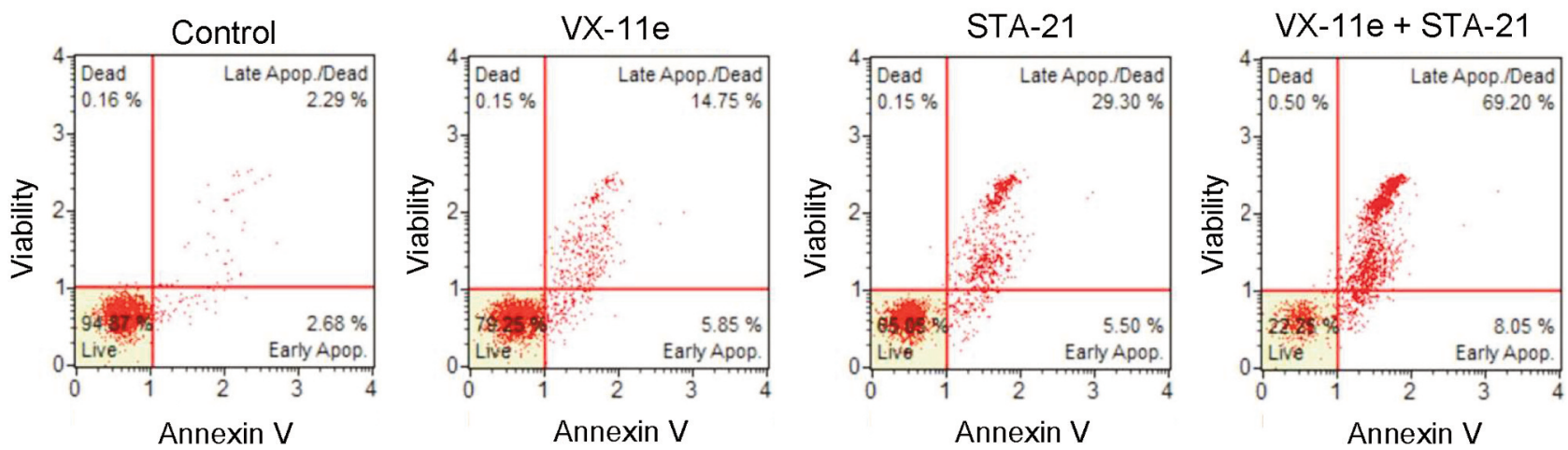

\section{MOLT-4}
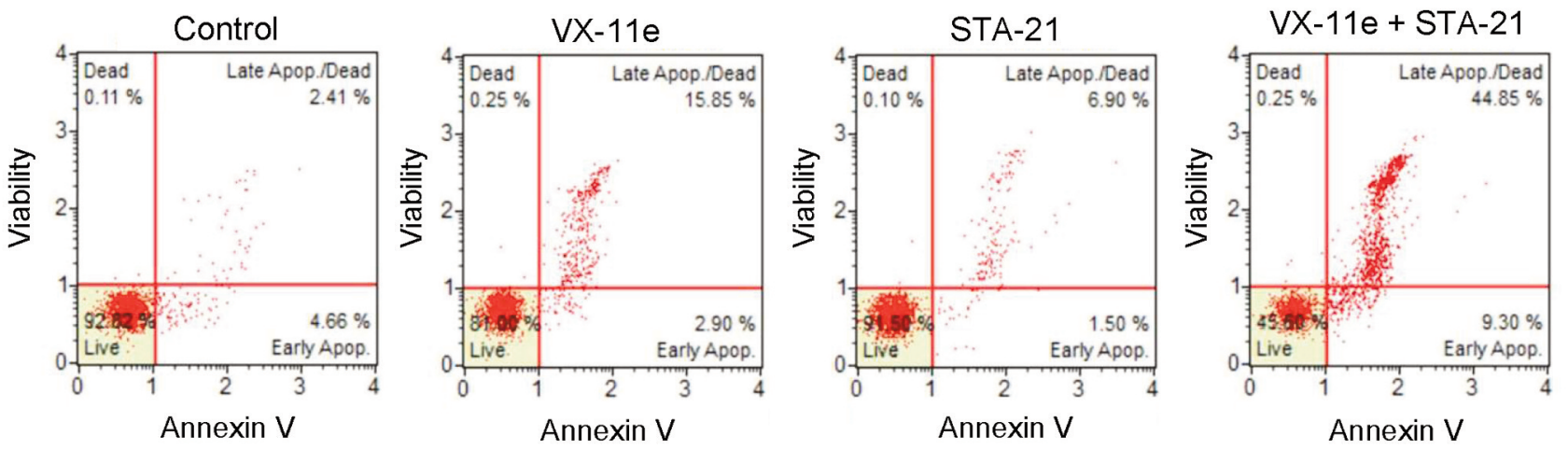

B

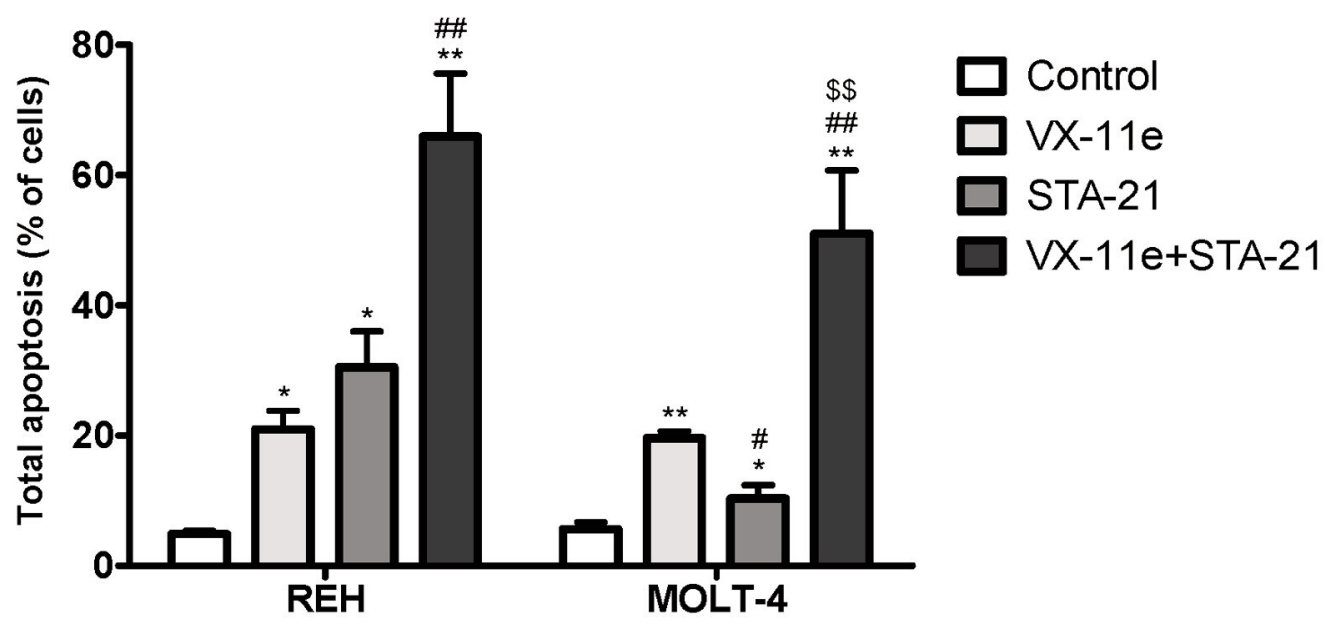

Figure 4. Combination of extracellular-regulated kinase (ERK) 2 inhibitor VX-11e and signal transducer and activator of transcription-3 (STAT3) inhibitor STA-21 enhanced apoptosis in acute lymphoblastic leukemia cells. REH and MOLT-4 cells were incubated for 48 with $4 \mu M$ VX-11e and 5 MM STA-21, alone and in combination. A: Representative dot plots of annexin V/7-aminoactinomycin D apoptotic assay. B: graph showing the percentage of apoptotic cells. Each value is the mean $\pm S D$ of three independent experiments. Significantly different at: ${ }^{*} p<0.05$, and $* * p<0.01$ vs. control; ${ }^{*} p<0.05$, and ${ }^{\# \#} p<0.01 \mathrm{vs}$. VX-11e alone; $\$ \$ p<0.01 \mathrm{vs}$. STA-21 alone. 
A
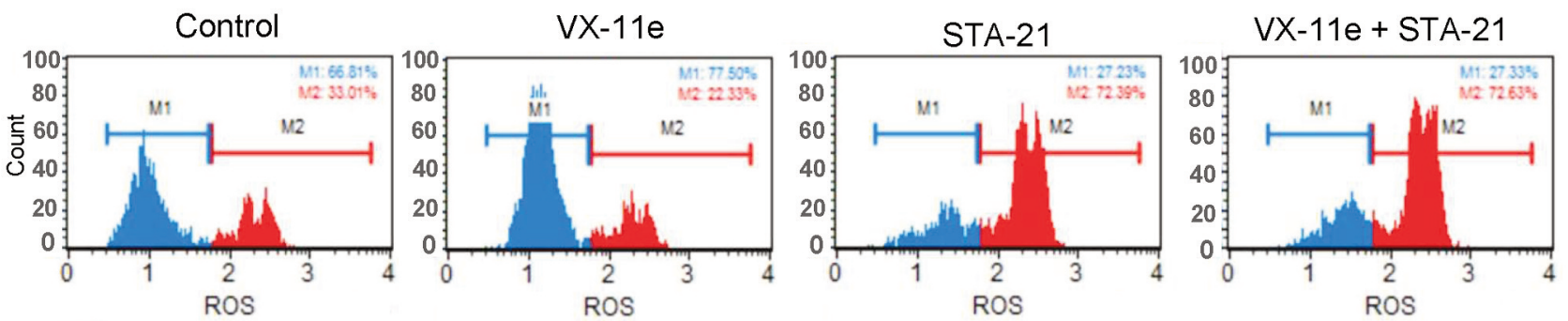

\section{MOLT-4}
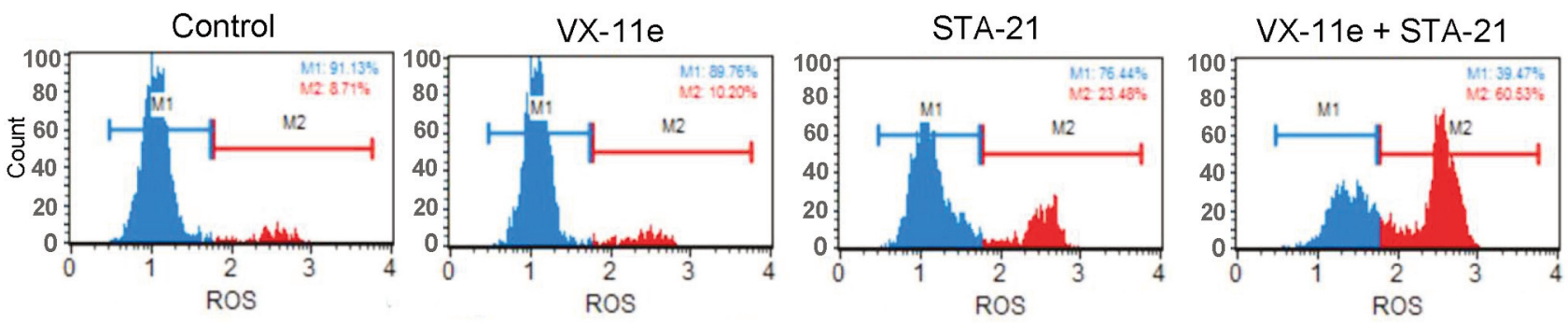

\section{B}

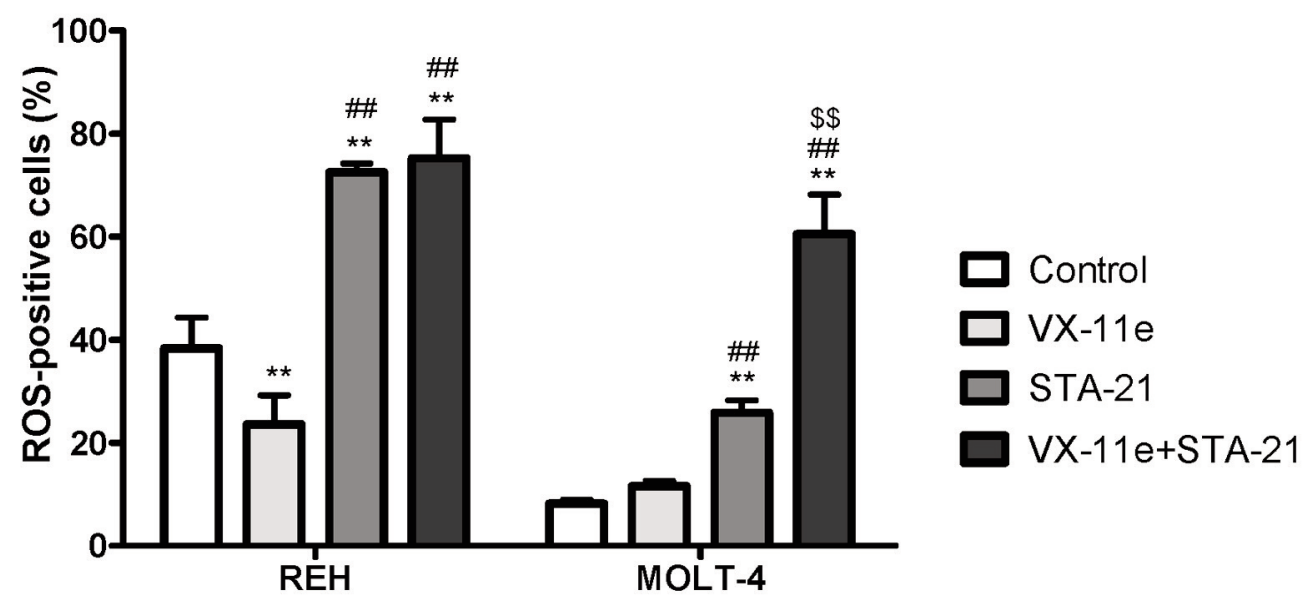

Figure 5. Combination of extracellular-regulated kinase (ERK) 2 inhibitor VX-11e and signal transducer and activator of transcription-3 (STAT3) inhibitor STA-21 enhanced reactive oxygen species (ROS) production in acute lymphoblastic leukemia cells. REH and MOLT-4 cells were incubated for 48 hours with $4 \mu M V X-11$ e and $5 \mu M$ STA-21, alone and in combination. A: Representative histograms of ROS-negative (M1) and ROS-positive (M2) cells. B: Graph showing the percentage of ROS-positive cells. Each value is the mean \pm SD of three independent experiments. Significantly different at: ${ }^{* *} p<0.01$ vs. control; ${ }^{\# \#} p<0.01$ vs. VX-11e alone; $\$ \$ p<0.01$ vs. STA-21 alone.

combination, we investigated related proteins. Treatment with these compounds alone and in combination did not affect the level of STAT3 in either cell line. VX-11e and STA-21 alone also had no effect on pSTAT3 protein, whereas their combination significantly reduced the pSTAT3 level in MOLT4 cells. VX-11e and STA-21 alone and in combination also did not influence the level of p53 protein. The amount of p21 in REH cells was markedly increased upon combined treatment, whereas expression of this protein was undetectable in MOLT- 4 cells, irrespective of the absence or presence of VX-11e and STA-21. The levels of survivin and PTP4A3 were significantly decreased in MOLT- 4 cells upon combined treatment when compared to control cells and cells treated with either inhibitor alone (Figure 6). These results suggest that the combination of VX-11e and STA-21 exerts its proapoptotic effect by up-regulating p21 in a p53-independent 
A

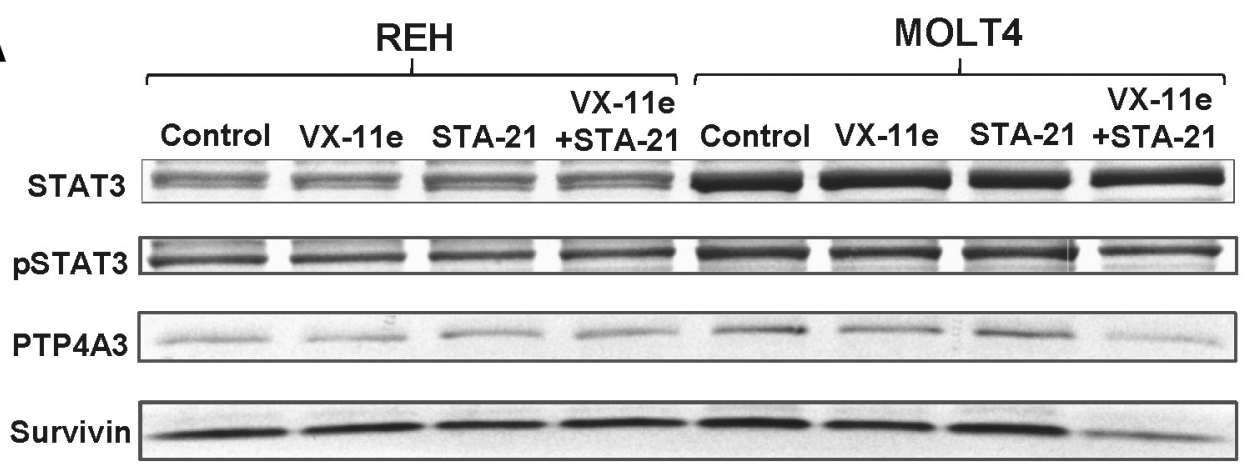

p53

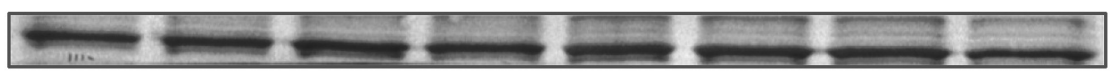

p21

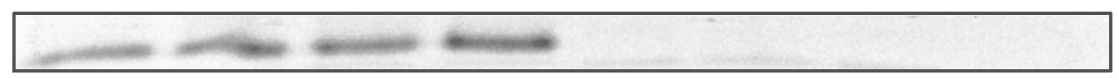

$\beta$-actin

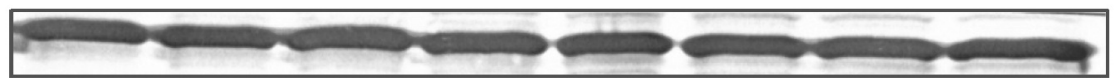

B

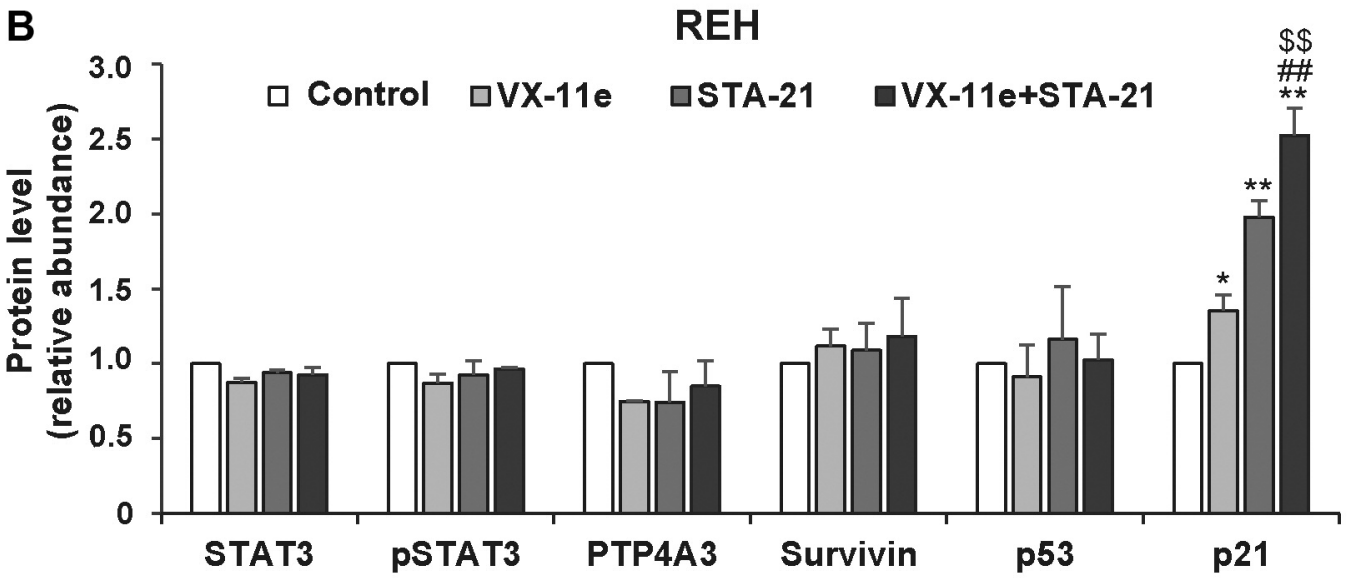

MOLT4

$\square$ Control $\square V X-11 e$ aSTA-21 $\square V X-11 e+S T A-21$

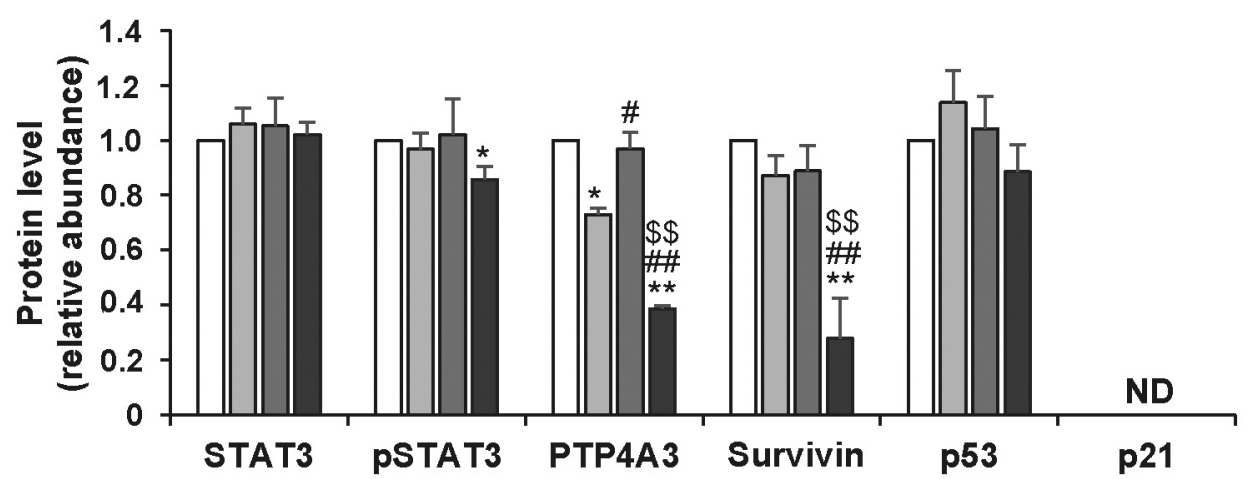

Figure 6. Combination of extracellular-regulated kinase (ERK) 2 inhibitor VX-11e and signal transducer and activator of transcription-3 (STAT3) inhibitor STA-21 affected levels of phospho ( $p$ )STAT3, p21, survivin and protein tyrosine phosphatase 4A3 (PTP4A3). REH and MOLT-4 cells were incubated for 48 hours with $4 \mu M$ VX-11e and $5 \mu M$ STA-21, alone and in combination. A: The level of STAT3, pSTAT3, p53, p21, survivin and PTP4A3 proteins was detected by western blot. $\beta$-Actin was used as a loading control. B: Quantification of proteins was performed by densitometric analysis and normalized to the internal loading control. Each value is the mean $\pm S D$ of three independent experiments. ND: Not detected. Significantly different at: ${ }^{*} p<0.05$, and ${ }^{*} p<0.01 \mathrm{vs}$. control; ${ }^{\#} p<0.05$, and ${ }^{\# \#} p<0.01 \mathrm{vs}$. VX-11e alone; $\$ \$ p<0.01$ vs. STA-21 alone. 
way in REH cells and by down-regulating pSTAT3, survivin and PTP4A3 in MOLT-4 cells.

\section{Discussion}

The combination of drugs that target different signaling pathways involved in the induction and progression of cancer may provide encouraging leads for anticancer therapy. In the present study, we have shown that a combination treatment using ERK2 inhibitor VX-11e and STAT3 inhibitor STA-21 enhanced anticancer effects in ALL cells by reducing viability, and inducing cell-cycle arrest, ROS production and apoptosis. We have demonstrated that VX-11e alone significantly inhibited ERK activity in both cell lines and this effect was maintained after combination with STA-21, especially in REH cells. Interestingly, STA-21 slightly but significantly reduced ERK activity in MOLT-4 cells. It was recently reported that STAT3 inhibitor HJC0152 affected ERK activity in gastric cancer cells (20). Moreover, we found that STA-21 alone had no effect on levels of total and phosphorylated STAT3 protein in either cell line. A possible explanation for our observations might be associated with the mechanism of action of STA-21. It has been demonstrated that a direct STAT3 inhibitor galiellalactone reduced STAT3 binding to DNA in prostate cancer cells, blocking the STAT3 signaling pathway without altering its phosphorylation (21). On the basis of these results, it is possible that in our study STA-21 inhibited STAT3 activation without affecting its phosphorylation status. However, VX-11e in combination with STA-21 reduced the level of phosphorylated STAT3 in MOLT-4 cells but not in REH cells. The drug response may vary depending on the cell line tested. Moreover, the different effect of VX-11e and STA-21 in combination on the level of pSTAT3 in REH and MOLT-4 cells might be due to expression of erythroblastosis variant gene 6 translocation (ETVO)-runt-related transcription factor 1 (RUNXI) fusion gene in REH cells, which regulates STAT3 phosphorylation (22). Taken together, we conclude that ERK signaling inhibition might influence STA-21 action leading to reduced STAT3 phosphorylation in MOLT-4 cells. However, our results do not exclude the involvement of other mechanisms.

Combined treatment with VX-11e and STA-21 induced G0/G1 cell-cycle arrest with a concomitant decrease in the G2/M population in both cell lines. Moreover, in REH cells this effect was associated with the increased protein level of the cell-cycle inhibitor p21, whereas in MOLT-4 cells, p21 expression was undetectable by western blotting in untreated and treated cells. It has been shown that p21 plays a crucial role in $\mathrm{G}_{1} / \mathrm{S}$ phase progression and its expression is $\mathrm{p} 53$ dependent (23). However, in this study we have found that the increase in $\mathrm{p} 21$ protein level might be regulated through a p53-independent mechanism in REH cells. Interestingly, some studies have demonstrated an anti-apoptotic role of p21 in leukemia cells (24-26). In contrast, it was shown that taxol increased p21 expression and induced growth arrest and apoptosis in breast cancer cells (27). Similarly, we have shown previously that combination of VX-11e with voreloxin increased the level of $\mathrm{p} 21$ protein in REH cells, leading to apoptosis (18).

Survivin, an inhibitor of apoptosis, plays a significant role in cell proliferation and survival (28), and its deregulated expression has been shown in hematopoietic malignancies, including ALL (29). While survivin has been identified as a gene downstream of STAT3, the inhibition of STAT3 may reduce the expression of survivin and induce apoptosis in hematological malignancies (30-32). Moreover, it was reported that survivin can be regulated by MEK/ERKdependent signaling (33). In this study we observed a significant reduction in the survivin level in MOLT-4 cells treated with both VX-11e and STA-21. Similarly, we found a decrease in survivin level in leukemia cell lines after combined treatment with VX-11e and voreloxin (18).

PTP4A3 participates in many cellular processes, such as proliferation, survival, motility and invasion $(34,35)$. PTP4A3 expression has been documented as being significantly elevated in a variety of solid tumor types compared with healthy tissues, as well as in acute myeloid leukemia (AML) and ALL cells (36, 37). In this study, we observed the level of PTP4A 3 to be reduced in MOLT- 4 cells treated with the combination of both drugs. Moreover, it has been demonstrated that STAT3 functionally regulates PTP4A3 expression in AML and that targeting either STAT3 or PTP4A3 reduced cell viability (35). It has also been found that knockdown of PTP $4 A 3$ reduced cell proliferation through enhanced production of reactive oxygen species in colon cancer cells (38).

ROS are considered to be essential in the regulation of proliferation, cell-cycle progression, differentiation, migration and cell death (39). An elevated ROS level plays a significant role in cancer treatment by inducing cell death through apoptosis $(40,41)$. We observed that apoptosis induced by combinatorial treatment with both VX-11e and STA-21 is related to enhanced ROS production. Interestingly, STA-21 alone significantly increased the ROS level in both cell lines as compared to control and VX-11e-treated cells, and this effect was markedly potentiated after combined treatment with VX11e in MOLT-4 cells. Similarly, in our previous study, the MEK inhibitor TAK-733 in combination with voreloxin increased ROS production in HL60 leukemia cells (10). Of note, the drug response in cancer cells may depend upon a variety of factors. In combinatorial treatment, one drug can sensitize cells to another drug by increasing ROS production $(42,43)$.

Apoptotic cell death can occur through different mechanisms depending on the cell type. Thus, it is possible that the proapoptotic effect of VX-11e and STA-21 in B-ALL REH cells might be due to an increased level of p21 protein, whereas reduction in pSTAT3, survivin and PTP4A3 protein levels after treatment with both drugs may enhance, at least in part, the 
apoptotic process in T-ALL MOLT-4 cells. It seems therefore possible that different mechanisms may be involved in the proapoptotic effects of VX-11e and STA-21 in REH and MOLT-4 cells. This intriguing finding requires further investigations.

\section{Conclusion}

Targeting cellular signaling pathways constitutes a promising therapeutic approach to the treatment of leukemia. As far as we are aware, this study is the first to demonstrate that ERK2 inhibitor VX-11e in combination with STAT3 inhibitor STA-21 promotes anticancer effects in ALL cell lines. Our findings provide a rationale for combining drugs targeting ERK and STAT3 pathways, potentially useful for the treatment of ALL.

\section{Conflicts of Interest}

None declared.

\section{Authors' Contributions}

EJG designed the research study. EJG and HJ performed the research. EJG, MJ and GJL analyzed the data. EJG wrote the article. JAL edited the article. All Authors read and approved the final article.

\section{Acknowledgements}

This study was supported by a grant N41/DBS/000063 from the Jagiellonian University Medical College.

\section{References}

1 Jemal A, Siegel R, Ward E, Hao Y, Xu J, Murray T and Thun MJ: Cancer statistics 2008. CA Cancer J Clin 58: 71-96, 2008. PMID: 18287387. DOI https://doi.orghttps://doi.orghttps://doi.org: 10.3322/CA.2007.0010

2 Hunger SP, Loh ML, Whitlock JA, Winick NJ, Carroll WL, Devidas M and Raetz EA: COG Acute Lymphoblastic Leukemia Committee. Children's Oncology Group's 2013 blueprint for research: Acute lymphoblastic leukemia. Pediatr Blood Cancer 60: 957-963, 2013. PMID: 23255467. DOI: 10.1002/pbc.24420

3 Knight $\mathrm{T}$ and Irving JA: RAS/RAF/MEK/ERK pathway activation in childhood acute lymphoblastic leukemia and its therapeutic targeting. Front Oncol 4: 160, 2014. PMID: 25009801. DOI: 10.3389/fonc. 2014.00160

4 Yoon S and Seger R: The extracellular signal-regulated kinase: Multiple substrates regulate diverse cellular functions. Growth Factors 24: 21-24, 2006. PMID: 16393692. DOI: 10.1080/026 99050500284218

5 Lefloch R, Pouysségur J and Lenormand P: Total ERK1/2 activity regulates cell proliferation. Cell Cycle 8: 705-711, 2009. PMID: 19242111. DOI: $10.4161 / \mathrm{cc} .8 .5 .7734$

6 Chung E and Kondo M: Role of RAS/RAF/MEK/ERK signaling in physiological hematopoiesis and leukemia development. Immunol Res 49: 248-268, 2011. PMID: 21170740. DOI: $10.1007 / \mathrm{s} 12026-010-8187-5$
7 Ünal EB, Uhlitz F and Blüthgen N: A compendium of ERK targets. FEBS Lett 591: 2607-2615, 2017. PMID: 28675784. DOI: $10.1002 / 1873-3468.12740$

8 Krepler C, Xiao M, Sproesser K, Brafford PA, Shannan B, Beqiri M, Liu Q, Xu W, Garman B, Nathanson KL, Xu X, Karakousis GC, Mills GB, Lu Y, Ahmed TA, Poulikakos PI, Caponigro G, Boehm M, Peters M, Schuchter LM, Weeraratna AT and Herlyn M: Personalized preclinical trials in BRAF inhibitor-resistant patient-derived xenograft models identify second-line combination therapies. Clin Cancer Res 22: 1592-1602, 2016. PMID: 26673799. DOI: 10.1158/1078-0432.CCR-15-1762

9 Shin M, Franks CE and Hsu KL: Isoform-selective activity-based profiling of ERK signaling. Chem Sci 9: 2419-2431, 2018. PMID: 29732117. DOI: $10.1039 / \mathrm{c} 8 \mathrm{sc} 00043 \mathrm{c}$

10 Jasek-Gajda, E, Gajda M, Jasińska M, Litwin JA and Lis GJ: TAK-733, a selective MEK inhibitor, enhances voreloxin-induced apoptosis in myeloid leukemia cells. Anticancer Res 38: 61476156, 2018. PMID: 30396931. DOI: 10.21873/anticanres.12967

11 Bowman T, Garcia R, Turkson J and Jove R: STATs in oncogenesis. Oncogene 19: 2474-2488, 2000. PMID: 10851046. DOI: $10.1038 /$ sj.onc. 1203527

12 Carpenter RL and Lo HW: STAT3 target genes relevant to human cancers. Cancers 6: 897-925, 2014. PMID: 24743777. DOI: 10.3390/cancers6020897

13 Xiong A, Yang Z, Shen Y, Zhou J and Shen Q: Transcription factor STAT3 as a novel molecular target for cancer prevention. Cancers 16: 926-957, 2014. PMID: 24743778. DOI: 10.3390/cancers6020926

14 Ishdorj G, Johnston JB and Gibson SB: Inhibition of constitutive activation of STAT3 by curcurbitacin-I (JSI 124) sensitized human B-leukemia cells to apoptosis. Mol Cancer Ther 9: 3302-3314, 2010. PMID: 21159613. DOI: 10.1158/1535-7163.MCT-10-0550

15 Song H, Wang R, Wang S and Lin J: A low-molecular-weight compound discovered through virtual database screening inhibits STAT3 function in breast cancer cells. Proc Nat Acad Sci USA 102: 4700-4705, 2005. PMID: 15781862. DOI: 10.1073/ pnas.0409894102

16 Jerez A, Clemente MJ, Makishima, H, Koskela H, Leblanc F, Peng Ng K, Olson T, Przychodzen B, Afable M, Gomez-Segui I, Guinta K, Durkin L, His ED, McGraw K, Zhang D, Wlodarski MW, Porkka K, Sekeres MA, List A, Mustjoki S, Loughran TP and Maciejewski JP: STAT3 mutations unify the pathogenesis of chronic lymphoproliferative disorders of NK cells and T-cell large granular lymphocyte leukemia. Blood 120: 3048-3057, 2000. PMID: 22859607. DOI: 10.1182/blood-2012-06-435297

$17 \mathrm{He}$ L, Tang J, Andersson EI, Timonen S, Koschmieder S, Wennerberg K, Mustjoki S and Aittokallio T: Patient-customized drug combination prediction and testing for T-cell prolymphocytic leukemia patients. Cancer Res 78: 2407-2418, 2018. PMID: 29483097. DOI: 10.1158/0008-5472.CAN-17-3644

18 Jasek-Gajda E, Jurkowska H, Jasińska M, Litwin JA and Lis GJ: Combination of ERK2 inhibitor VX-11e and voreloxin synergistically enhances anti-proliferative and pro-apoptotic effects in leukemia cells. Apoptosis 24: 849-861, 2019. PMID: 31482470. DOI: 10.1007/s10495-019-01564-6

19 Nagathihalli NS, Castellanos, JA, Lamichhane P, Messaggio F, Shi C, Dai X, Rai P, Chen X, VanSaun MN and Merchant NB: Inverse correlation of STAT3 and MEK signaling mediates resistance to RAS pathway inhibition in pancreatic cancer. Cancer Res 78: 6235-6246. 2018. PMID: 30154150. DOI: 10.1158/00085472.CAN-18-0634 
20 Jiang X, Wu M, Xu Z, Wang H, Wang H, Yu X, Li Z and Teng L: HJC0152, a novel STAT3 inhibitor with promising anti-tumor effect in gastric cancer. Cancer Manag Res 10: 6857-6867, 2018. PMID: 30588091. DOI: 10.2147/CMAR.S188364

21 Don-Doncow N, Escobar Z, Johansson M. Kjellström S, Garcia V, Munoz E, Sterner O, Bjartell A and Hellsten R: Galiellalactone is a direct inhibitor of the transcription factor STAT3 in prostate cancer cells. J Biol Chem 289: 15969-15978, 2014. PMID: 24755219. DOI: $10.1074 / j b c . M 114.564252$

22 Mangolini M, de Boer J, Walf-Vorderwülbecke V, Pieters R, den Boer ML and Williams O: STAT3 mediates oncogenic addiction to TEL-AML1 in t(12;21) acute lymphoblastic leukemia. Blood 122: 542-549, 2013. PMID: 23741012. DOI: 10.1182/blood-2012$11-465252$

23 Sherr CJ and Roberts JM: CDK inhibitors: positive and negative regulators of $\mathrm{G}_{1}$-phase progression. Genes Dev 13: 1501-1512, 1999. PMID: 10385618. DOI: 10.1101/gad.13.12.1501

24 Chang BD, Watanabe K, Broude EV, Fang J, Poole JC, Kalinichenko TV and Roninson IB: Effects of p21 WAF1/CIP1/SDI on cellular gene expression: Implications for carcinogenesis, senescence, and age-related diseases. Proc Natl Acad Sci USA 97: 4291-4296, 2000. PMID: 10760295. DOI: 10.1073/pnas.97.8.4291

$25 \mathrm{Wu}$ X, Yang, N, Zhou WH, Xu J, Chen JJ, Zheng FM, Long ZJ, Yue CF, Ai KX, Liu LL, Wan XY and Liu Q: Up-regulation of p21 inhibits TRAIL-mediated extrinsic apoptosis, contributing resistance to SAHA in acute myeloid leukemia cells. Cell Physiol Biochem 234: 506-518, 2014. PMID: 25116350. DOI: 10.1159/000363018

26 Javelaud D and Besancon F: Inactivation of p21 WAF1 sensitizes cells to apoptosis via an increase of both $\mathrm{p} 14 \mathrm{ARF}$ and $\mathrm{p} 53$ levels and an alteration of the BAX/BCL-2 ratio. J Biol Chem 277: 37949-37954, 2002. PMID: 12151395. DOI: 10.1074/jbc.M20 4497200

27 Choi YH and Yoo YH: Taxol-induced growth arrest and apoptosis is associated with the upregulation of the CDK inhibitor, p21 WAF1/CIP1, in human breast cancer cells. Oncol Rep 28: 21632169, 2012. PMID: 23023313. DOI: 10.3892/or.2012.2060

$28 \mathrm{Li} \mathrm{D}, \mathrm{Hu} \mathrm{C}$ and $\mathrm{Li} \mathrm{H}$ : Survivin as a novel target protein for reducing the proliferation of cancer cells. Biomed Rep 8: 399-406, 2018. PMID: 29725522. DOI: 10.3892/br.2018.1077

29 Bhojwani D, Kang, H, Moskowitz NP, Min DJ, Lee H, Potter JW, Davidson G, Willman CL, Borowitz MJ, Belitskaya-Levy I, Hunger SP, Raetz EA and Carroll WL: Biologic pathways associated with relapse in childhood acute lymphoblastic leukemia: A Children's Oncology Group study. Blood 108: 711-717, 2006. PMID: 16822902. DOI: 10.1182/blood-2006-02-002824

30 Aoki Y, Feldman GM and Tosato G: Inhibition of STAT3 signaling induces apoptosis and decreases survivin expression in primary effusion lymphoma. Blood 101: 1535-1542, 2003. PMID: 12393476. DOI: 10.1182/blood-2002-07-2130

31 Gritsko T, Williams A, Turkson J, Kaneko S, Bowman T, Huang M, Nam S, Eweis I, Diaz N, Sullivan D, Yoder S, Enkemann S, Eschrich S, Lee JH, Beam CA, Cheng J, Minton S, Muro-Cacho CA and Jove R: Persistent activation of STAT3 signaling induces survivin gene expression and confers resistance to apoptosis in human breast cancer cells. Clin Cancer Res 12: 11-19, 2006. PMID: 16397018. DOI: 10.1158/1078-0432.CCR-04-1752

32 Quoc Trung L, Espinoza JL, Takami A and Nakao S: Resveratrol induces cell-cycle arrest and apoptosis in malignant NK cells via JAK2/STAT3 pathway inhibition. PLoS One 8: e55183, 2013. PMID: 23372833. DOI: 10.1371/journal.pone.0055183
33 Carter BZ, Milella M, Altieri DC and Andreeff M: Cytokineregulated expression of survivin in myeloid leukemia. Blood 97: 2784-2789, 2001. PMID: 11313272. DOI: 10.1182/blood.v97.9.2784

34 Campbell AM and Zhang ZY: Phosphatase of regenerating liver: A novel target for cancer therapy. Expert Opin Ther Targets 18: 555-569, 2014. PMID: 24579927. DOI: 10.1517/14728222. 2014.892926

35 Zhou J, Chong PS, Lu X, Cheong LL, Bi C, Liu SC, Zhou Y, Tan TZ, Yang H, Chung TH, Zeng Q and Chng WJ: Phosphatase of regenerating liver- 3 is regulated by signal transducer and activator of transcription 3 in acute myeloid leukemia. Exp Hematol 42: 1041-1052, 2014. PMID: 25139404. DOI: 10.1016/j.exphem. 2014.08.001

36 Park JE, Yuen HF, Zhou JB, Al-Aidaroos AQ, Guo K, Valk PJ, Zhang SD, Chng WJ, Hong CW, Mills K and Zeng Q: Oncogenic roles of PRL-3 in FLT3-ITD induced acute myeloid leukaemia. EMBO Mol Med 5: 1351-1366, 2013. PMID: 23929599. DOI: 10.1002/emmm.201202183

37 Grönroos T, Teppo S, Mehtonen J, Laukkanen S, Liuksiala T, Nykter M, Heinäniemi M and Lohi O: Overexpression of PTP4A3 in ETV6-RUNX1 acute lymphoblastic leukemia. Leuk Res 54: 16, 2017. PMID: 28063378. DOI: 10.1016/j.leukres.2016.12.005

38 Lian S, Meng L, Yang Y, Ma T, Xing X, Feng Q, Song Q, Liu C, Tian Z, Qu L and Shou C: PRL-3 promotes telomere deprotection and chromosomal instability. Nucleic Acids Res 45: 6546-6571, 2017. PMID: 28482095. DOI: 10.1093/nar/gkx392

39 Covarrubias L, Hernández-García D, Schnabel D, Salas-Vidal E and Castro-Obregón S: Function of reactive oxygen species during animal development: Passive or active? Dev Biol 320: 1-11, 2008. PMID: 18555213. DOI: 10.1016/j.ydbio.2008.04.041

40 Heasman SA, Zaitseva L, Bowles KM, Rushworth SA and Macewan DJ: Protection of acute myeloid leukaemia cells from apoptosis induced by front-line chemotherapeutics is mediated by haem oxygenase-1. Oncotarget 2: 658-668, 2011. PMID: 219119 19. DOI: 10.18632 /oncotarget. 321

41 Chen P, Luo X, Nie P, Wu B, Xu W, Shi X, Chang H, Li B, Yu X and Zou Z: CQ synergistically sensitizes human colorectal cancer cells to SN-38/CPT-11 through lysosomal and mitochondrial apoptotic pathway via p53-ROS cross-talk. Free Radic Biol Med 104: 280-297, 2017. PMID: 28131902. DOI: 10.1016/j.freerad biomed.2017.01.033

42 Gao S, Mobley A, Miller C, Boklan J and Chandra J: Potentiation of reactive oxygen species is a marker for synergistic cytotoxicity of MS-275 and 5-azacytidine in leukemic cells. Leuk Res 32: 771780, 2008. PMID: 18031811. 10.1016/j.leukres.2007.09.007

43 Wan MJ, Liu S, Liu Y and Zheng D: Actinomycin D enhances TRAIL-induced caspase-dependent and -independent apoptosis in SH-SY5Y neuroblastoma cells. Neurosci Res 59: 40-46, 2007. PMID: 17707539. DOI: 10.1016/j.neures.2007.05.010

Received May 5, 2020

Revised June 1, 2020

Accepted June 10, 2020 